\title{
A Cultural Psychological Theory of Mental Illness, Sup- ported by Research in Saudi Arabia
}

\author{
Carl Ratner \\ Imam University, Saudi Arabia \\ El-Sayed El-Badwi \\ Riyadh, Saudi Arabia
}

This article proposes a theory of psychological disturbance (mental illness) as a cultural phenomenon. The theory is based on - and extends -- the general cultural psychological theory of Vygotsky, Luria, and Leontiev, as well as the specific social approach to psychopathy of Fromm, Foucault, Laing, and Rieber. We demonstrate that the psychodynamics of individual disturbances are shaped by normative, macro cultural factors, such as gender norms, religious doctrine, family structure, architecture, and clothing. We illustrate this cultural psychological analysis of individual psychology with a case study of a 25 year old Saudi obsessive compulsive patient in Riyadh backed by 50 interviews with students about family relations in Saudi Arabia. We discuss the therapeutic and political implications of our cultural theory of psychological disturbance.

Keywords: mental illness, cultural psychology, Saudi Arabia, Vygotsky, Saudi family, Islam, OCD, scrupulosity, macro cultural factors, hajib, gender, Leontiev, emotions, political, ideology, cross-cultural psychology, psychological anthropology 


\section{Introduction to Cultural Psychology}

In this paper, we draw upon the general cultural psychological perspective developed by Urie Bronfenbrenner, Vygotsky, Luria, A.N. Leontiev, and Carl Ratner, along with a specific cultural view of psychopathology articulated by Eric Fromm, Foucault, Laing, and Rieber, to provide a framework for a theory of psychological disturbance/mental illness. ${ }^{1}$ We explain its scientific potential for comprehending mental illness, its therapeutic application, and its political potential for mitigating psychological distress.

Bronfenbrenner conceptualized psychology as formed by a network of cultural factors. He conceptualized this network as a set of concentric circles with micro level interactions surrounded by meso-level factors, and ultimately by macro cultural factors which are social policies, overarching patterns of ideology and organization of the social institutions common to a particular culture or subculture. "Public policy is a part of the macro system determining the specific properties of exo-, meso-, and microsystems that occur at the level of everyday life and steer the course of behavior and development" (Bronfenbrenner, 1979, pp. 8-9; Ratner, 1991, pp. 172-178).

In his article "Activity and Consciousness" (available online: http:// www.marxists.org/archive/leontev/works/1977/leon1977.htm)Leontiev (1977) says: "Despite all its diversity, all its special features, the activity [Tatigkeit] of the human individual is a system that obeys the system of relations of society. Outside these relations human activity does not exist. How it exists is determined by the forms and means of material and spiritual

\footnotetext{
1 In this paper we use psychological disturbance interchangeably with the more widely used term mental illness. We are cognizant of the terminological difficulties of these terms and do not wish to address them here. We are using these terms non-technically to refer to the panoply of severe, incapacitating psychological problems, beyond the everyday, bothersome, "normal" problems - e.g., a Saudi patient who is a compulsive masturbator and has obsessive fears that his ejaculated semen enters his body through his rectum and impregnates him.
} 
communication that are generated by the development of production and that cannot be realised except in the activity of specific individuals. It stands to reason that the activity of every individual depends on his place in society, on his conditions of life."

Leontiev provides an important discussion of personal meanings in relation to social activity and collective representations. His comments bear directly on psychological disturbance which is a kind of personal meaning that individuals under stress use to make sense of their stressful worlds. Leontiev acknowledges personal meanings as an idiosyncratic sense of the complex of experiences that comprise one's personal life. "Whereas external sensuousness associates objective meanings with the reality of the objective world in the subject's consciousness, the personal meaning associates them with the reality of his own life in this world, with its motivations. It is the personal meaning that gives human consciousness its partiality." Leontiev goes on to explain that personal meanings about one's own life are not free inventions. They draw on social values and concepts to interpret personal events (such as family psychological abuse). "In contrast to society the individual has no special language of his own with meanings that he has evolved himself. His comprehension of reality can take place only by means of the 'readymade' meanings he assimilates from without - the knowledge, concepts, and views he receives through intercourse, in the various forms of individual and mass communication. This is what makes it possible to introduce into his consciousness or even impose upon that consciousness distorted or fantastic notions and ideas, including those that have no basis in his real, practical life experience." Social meanings are so powerful that they may distort individuals' lived experiences. This is an important dynamic in psychological disturbance where parents may impose their peculiar interpretations of family events onto their children's experiences. In addition, stressed individuals generally adopt 
exaggerated forms of cultural values and practices as guides for interpreting and reacting to stress.

Leontiev correctly observes that the social structuring of personal meanings is not always successful and complete. Discrepancies erupt. "There is no disappearance (nor could there be) of the constantly proliferating discrepancy between personal meanings which carry the intentionality, the partiality of the subject's consciousness, and the objective meanings, which though 'indifferent' to them are the sole means by which personal meanings can be expressed."

Leontiev subsumes even the most arcane psychological processes within a cultural framework: "although a scientific psychology must never lose sight of man's inner world, the study of this inner world cannot be divorced from a study of his activity and does not constitute any special trend of scientific psychological investigation." This applies to the arcane inner world of psychological disturbance.

Ratner has extended Bronfenbrenner's and Leontiev's model to articulate macro cultural factors in detail and their complex interdependence with psychology. Ratner's theory is called macro cultural psychology (Ratner, 2007, 2011a, b, c, d, 2012). The main point is that psychological phenomena are organically part of macro cultural factors. Psychological phenomena originate in macro cultural factors, they are the subjectivity that establishes and maintains macro cultural factors, and they take on the characteristics of macro cultural factors. Macro cultural factors stimulate, shape, support, and socialize psychological phenomena. For instance, inventing and using new instruments stimulates, shapes, and supports new perceptual competencies; developing and occupying new social roles for women, children, and men stimulates, shapes, supports and socialized new emotional capabilities; new economic formations such as the free market require, stimulate, shape, and support an 
individualistic self concept that takes personal responsibility for finding jobs and negotiating salaries; different forms of education - apprenticeship vs. formal education - require, stimulate, shape, and support different cognitive and motivational competencies.

An example of how social roles shape emotions comes from our research in Saudi Arabia. Saudi male college students reported (in interviews to be described below) their fathers are generally rigid authority figures in the family. When asked if they resented this suppression of their own ideas, students reported they accept his right to be correct and to deny contradiction. For a day or so, they feel disappointed about bottling up opinions, but then it dissipates and does not bother them. They do not suppress sadness, they cognitively reinterpret it in terms of social standing of father and child. They are encouraged to do so by their friends and mother. "He's your father, he is wise, he has the right to keep his opinion, you should listen to your father, don't be angry at him, respect him, do not disturb him during his quiet time at home." This social-cognitive (re)construction of resentment transforms it either into a non-event that dissipates, or else into guilt at having disturbed the father. Either of these leaves the individuals feeling distant from their father but not resentful. To resent him would be to deny the social structure of his authority. It would impugn his wisdom and challenge his authority to make decisions and control his children. If children re-formulate their anger as unjustified or harmful, this preserves the social system of the father's authority. This is why all subjects reported they have never fought with their fathers in the sense of yelling, calling names, slamming doors, refusing to do something.

This example shows how family emotions carry (incarnate), express, and support social roles, social relations, and social structures. Emotions are political; emotions are social agents that animate social behavior. It is 
imperative that people feel the socially appropriate emotion if the social system is to be maintained. Emotional reactions have a cultural basis and function. Individual emotions derive from cultural ones, as Vygotsky emphasized. ${ }^{2}$

Dwairy \& Van Sickle (1996) observe an additional way in which psychological dynamics reflect Saudi society: "Repression is an inevitable consequence of traditional Arabic society. It is the intrapsychic means by which social condemnation can be avoided and vital social support maintained." "The Arabic individual experiences control as external (i.e., coming from the family and society), whereas in Western culture much control of the individual's life is experienced as internal and personal. "Similarly, projection and external attribution are fostered rather than personal responsibility and self-efficacy" (pp. 233, 234).

A last example of Saudi macro cultural psychology concerns psychological dynamics in marriage. Where marriage partners are personally chosen, as in the West, the choice is guided by complex psychological dynamics to fulfill needs, support idiosyncrasies, maintain a psychological comfort zone, and compensate for social and psychological deficits. Where marriages are arranged by parents, as in Saudi Arabia, and to a lesser extent in India, the psychological dynamics of the individual partners are largely eliminated from consideration. Thus, psychological dynamics for marriage are culturally fostered and culturally functional. Using psychological dynamics to select a spouse ensures that the marriage institution will be a personal, voluntary onewhich reflects and supports broader forms of individualism and democracy in

2 Emotions are not personal expressions. The fact that someone likes or dislikes something should not be accepted/respected as inviolable, authentic expressions of self. They should be analyzed for their cultural basis, character, and function. For instance, the fact that someone detests the sight of interracial couples should be condemned as reflecting racism. The fact that Saudi Islamic women feel embarrassed if they are seen unveiled by men who are not family members should be analyzed for its political basis, character, and function which is to segregate and restrict women; their feeling should not be uncritically respected any more than disgust at interracial romance should be. 
society. Circumventing psychological dynamics in selecting a spouse ensures that the marriage institution will be arranged without significant interference from personal wishes - and this reflects and supports lack of individualism and democracy in society. ${ }^{3}$

These examples illustrate a new sense of psychology's origins, locus, characteristics, and function - in macro cultural factors.

Shweder $(1990$, pp. 1, 24) expressed some of this sense in his statement, "Cultural psychology is the study of the way cultural traditions and social practices regulate, express, transform, and permute the human psyche, resulting less in psychic unity for humankind than in ethnic divergences in mind, self, and emotion." "In the language of cultural psychology there are no pure psychological laws, just as there are no unreconstructed or unmediated stimulus events...Cultural psychology signals an end to the purely psychological in psychology..." Vygotsky similarly maintained that "Higher mental functions [are] the product of the historical development of humanity." "The structures of higher mental functions represent a cast of collective social relations between people. These [mental] structures are nothing other than a transfer into the personality of an inward relation of a social order that constitutes the basis of the social structure of the human personality" (Vygotsky, 1998, pp. 34, 169-170, emphasis added).

3 Some interesting exceptions occur when families carefully investigate the prospective spouse in order to learn about his/her psychology. This investigation includes speaking to friends of the families to learn their opinions of the prospective spouse, and also includes visits to the mosque to interview neighbors, and visits to the workplace to learn from co-workers and managers about the personality and habits of the prospective spouse. Interviewees expect these kinds of visits and are expected to be truthful about faults and virtues.

Institutionalized, administered forms of marriage testify to the fact that seemingly personal acts, such as marriage, are actually macro cultural factors. American free marriage is institutionalized and codified in law and defines/shapes society. If parents attempt to arrange a marriage for their child, the child has legal grounds for refusing. Free, personal choice is a social and legal imperative in the West. 


\section{Macro Cultural Psychology and Psychological Disturbance}

Applying these concepts of macro cultural psychology to explain psychological disturbance, we must trace the latter to elements of the social order. Psychological disturbance must be treated as a reflection of disturbing elements of the social order, particularly when psychological disturbance is prevalent. High social prevalence cannot be explained by individual factors. Macro cultural psychology outlines a theory of this relationship between psychological disturbance and disturbing macro cultural factors in the following points:

1) Normative macro cultural factors (in most societies) contain deleterious elements in combination with benevolent elements. Troublesome elements include militarism, alienation, exploitation, discrimination, poverty. Ratner terms these "the politics of disaster;" Rieber (1997) calls them "psychopathy of everyday life"; Fromm (2010) calls them "pathology of normalcy and normal pathology". The positive and negative sets of elements modulate each other: positive elements soften negative ones, and negative ones corrupt positive ones.

For instance, unemployment is a negative cultural element of the market economy. It makes work insecure and stressful. However, in most countries, worker unions work to contain unemployment (and the negative effects of commodified labor) and to pressure the government to provide temporary relief for the unemployed. This cushions the adverse effects of unemployment.

2) Positive and negative elements of macro cultural factors elicit, shape, support, and socialize corresponding psychological attributes. The relative balance of positive and negative psychological elements 
is a function of the relative weight of positive and negative cultural elements.

3) The presence of negative/pathological elements in normal society generates "normative" psychological problems in people. Fromm termed this "socially patterned defects"; Ratner (2011d, 2012b) calls it "the psychology of oppression"and "false consciousness". Examples are: normal Americans are stressed to the point that approximately one-third take psychotropic medicines to cope. (Antidepressants are the second leading drug prescribed in the U.S., after statins for cholesterol.) Additional millions cope with distress in other debilitating ways such as substance abuse. 34,000 Americans commit suicide each year. Americans kill each other at the rate of 16,000 a year. As serious as these behavioral problems are, they are not considered to be insanity, madness, or mental illness.

A cross-cultural example of pathological normalcy is the fact that China's suicide rate is 2.3 times the world average. Recent statistics show that more than 287,000 Chinese end their own lives every year, with another 3 million attempting suicide. Suicide is one of the top five causes of death in mainland China, and the leading cause of death for 15- to 34-year-olds. (China is the only country where suicides among women outnumber those among men. in Taiwan, by contrast, two-thirds of suicides are male. China is also one of the few countries where rural suicides outnumber urban suicides; Ratner, 2011a, pp. vii-viii).

These psychological problems are generated by debilitating aspects of normative macro cultural factors.

4) Under certain conditions, positive social factors are diminished, and deleterious cultural elements become prominent, concentrated, 
amplified, and intensified in the lives of certain people. An unemployed worker may not be eligible for government benefits, or they may expire after a certain time. Or, social policy may reduce unemployment benefits in general. The change in social policy intensifies this troublesome social element and extends it to more individuals.

5) These debilitating social factors, generate severe psychological disturbance/madness/mental illness in people who are exposed to them. They do so directly (as in the case of war, unemployment, poverty, discrimination, and alienation) and indirectly through disturbed family interactions that are fostered by and transmit intense social pathology.

This is the only way to explain the high prevalence of psychological disturbance - e.g., the National Institute of Mental Health estimates that $46 \%$ of Americans have had at least one mental illness some time in their lives. Mental illness is now the leading disability among American children (Angell, 2011). The 1-month prevalence of mental disorder in China is $17.5 \%$ of the population (Ratner, 2011a, pp. vii-viii). Severe psychological disturbance is generated by severely disturbing macro cultural factors, just as normal psychological disturbance is generated by debilitating aspects of normal macro cultural factors (as in point \#3).

The point here is that the disturbing cultural factors which foster psychological disturbance are normal macro cultural factors that contain normally troublesome features. It is the intensification of normally troublesome features of normal macro cultural factors that generates psychological disturbance. Severe disturbance is continuous with normal pathology; it is not qualitatively different, alien to, or 
antithetical to normal cultural factors. Severe disturbance occurs within normal cultural factors whenever their debilitating elements "leach out" from their compensatory positive elements and nakedly disturb numbers of individuals - as when unemployment benefits expire, or when social leaders intensify society's negative elements and strip away compensatory positive elements - through stronger exploitation, discrimination, job deskilling, job displacement, wage and pension reductions, disempowering unions, closing opportunities for fulfillment, militarism, dismantling the social support system. (This view is endorsed by The American Psychological Association's Task Force on Socioeconomic Status - APA, 2002.)

Social and psychological disruptions are an indicator of deleterious macro cultural factors (the politics of disaster) and the need to transform them. (Of course, defenders of the status quo reject this analysis. They respond to social and psychological disruptions with increased security for macro cultural factors, and greater suppression of behavior that challenges them.)

This cultural (Vygotskyian) analysis of psychological disturbance as stemming from the psychopathology of everyday macro cultural factors has been suggested in less specific terms by Fromm (2010), Foucault (1987), Sass (1992), Ratner (1970), Ratner (1991, chap. 6), Ratner (2011a, b, c, d), Ratner (2012a, b), Rieber (1997), and Laing (1967). 
Our account may be schematically depicted as follows:

Figure One

The Cultural Basis of Psychological Disturbance

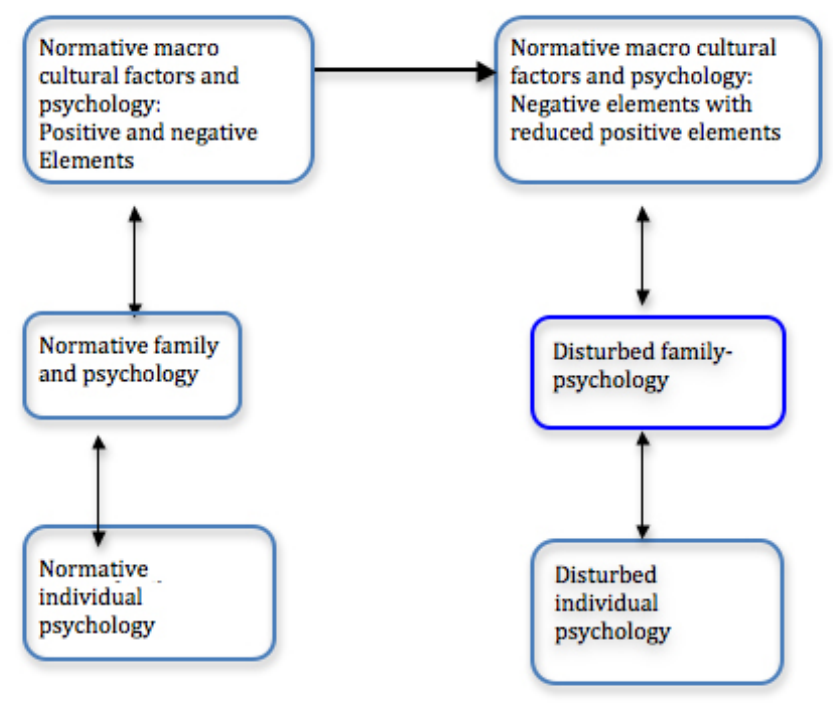

Figure one shows that disturbed family interactions and psychology emanate from the same social system and psychology that normal family interactions do. The difference is that disturbed families are exposed to the deleterious elements of cultural factors in a more concentrated form. Normal families' exposure to these elements is buffered by positive elements of the macro cultural factors. Normal families are impaired by the deleterious normal elements, but not as seriously as people who are exposed to undiluted doses.

Unprotected intercourse with normative pathogens can cause the birth of unwanted (deleterious) psychological consequences. This is why the prevalence of mental illness is highly correlated with negative cultural phenomena such as unemployment and low social class (Ratner, 1991, chaps. $4,5,6)$. 
The right hand column of disturbed social-psychological phenomena is parallel to and continuous with the normative left hand column. The right is a variant, or derivative, of the left at every level.

The model explains the causes, prevalence, and character of individual psychological disturbance but not on the individual level, in terms of individual mechanisms. We explain individual psychology in terms of cultural processes, as Vygotsky and Shweder advocate. We can go from there to reforming culture to prevent this kind of disturbing experience from recurring.

The vertical categories in figure one are also variants of each other: The family is a variant of macro cultural factors, and individual psychology is a variant of both of these. In addition, the upper levels of figure one are reciprocally affected by the lower levels.

What is central to our analysis is that culture generates both the oppressive treatment of people and their ways of experiencing it, suffering, or "illness". Other approaches limit culture to one side of this interaction. They postulate culture as a stress that individual react to on the basis of personal or natural processes - as the diathesis-stress model and the co-constructionist models claim. Or, stress is naturalized (as "conflict," or "frustration," or "misfortune,") while culture is confined to shaping the ways that stress is interpreted, perceived, or experienced. Our view emphasizes that culture is the social ways that people are treated, and the ways they experience and react to that treatment.

Kleinman and Kleinman (1985, pp. 469-471) elucidate this process in the case of psychological disturbance caused by the Chinese Cultural Revolution.

Our patients appear to have been at higher risk because of their place in local Chinese contexts of power and the sociopolitical 
and historical changes those contexts had undergone. A number of our patients came from highly stigmatized families that carried the "black" labels of rightist or landlord background. Growing up in that setting, our future patients had faced great discrimination and blocked access to resources (senior middle school, university, desirable jobs). Many had internalized a spoiled identity, one that was dramatically reaffirmed in large national campaigns in which techniques for enhancing feelings of shame and guilt (self-criticism sessions, criticism of and by family members and family friends) were regularly employed, and in which their traditional Chinese moral universe was literally stood on its head. The children of "stinking intellectuals" learned to criticize themselves and their families, for example, the very intellectual values so central to China's millennial culture and most probably an active socializing force in their very families. More practically, they were sent to the "distant" (most impoverished) countryside to live with peasants, where they often were greeted with hostility and suspicion in the peasant world of limited goods: where the rusticated youth were seen as a threat... When they finally returned from the countryside they found themselves literally "lost."...A few became so deeply embittered that every aspect of their lives radiated anger and hatred and alienation; others withdrew with fear and hurt into the inner privacy of the isolated self...

Chinese culture affected this social psychological and sociosomatic process of disease production in the creation [i.e., definition, interpretation] of particular kinds of stressors (self-criticism sessions, being sent to the countryside, etc.), the 
valuation of certain types of stressors as most stressful (those that broke up family system or undermined the sociocentric moral underpinnings of the Chinese self), and the labeling of psychophysiological reactions these stressors produced as "neurasthenia," to which the tendency to amplify that somatic component and dampen the psychological component of the stress response contributed. Chinese culture also affected the pattern of excessive medical help seeking, the use of particular styles of illness behavior to communicate social and personal distress...(e.g., the cultural rules governing how loss should be responded to).

This is a comprehensive summary of the complex ways that concrete cultural factors - such as political movements and ideology -- treat people, position them socially and geographically, define behavior, define subjectivity, and define things. The Cultural Revolution punished (publicly denounced, imprisoned, and killed) people for certain behaviors; it placed them in particular social positions (fired from jobs and political positions), imposed a stigmatized social identity on them, forced others to treat them in certain ways, forced the victims to think of themselves in certain ways and to act in certain ways (self-criticism), caused them to experience anxiety, confusion, inadequacy, guilt, anger, shame, and depression. Chinese culture also defined the concrete form that these psychological states took. Guilt was generated by blaming the victim for letting his family down and turning the family against the him, which are devastating charges in Chinese family-oriented culture that assuredly generate guilt. Chinese cultural values (e.g., medical concepts) channeled morbid experience into psychosomatic symptoms. Of course, individuals synthesize ("totalize") these elements into a coherent sense of 
themselves, their experiences, the world, and how to act on them. However, the elements are cultural products of Chinese history.

\section{Cross-Cultural Psychology and Psychological Anthropology}

We suggest that this macro cultural psychological theory/model of psychological disturbance is more complete and fine-grained than accounts by cross-cultural psychologists and psychological anthropologists. They document correlations between cultural factors and mental illness. What is lacking, however, is the internal relation between culture and mental illness that we have outlined, and the relation between mental illness and general (normal) psychology. That is, what is culture and how is it organized? What are the most important cultural factors? Why do they foster mental illness? what about them fosters mental illness? What accounts for the prevalence rate of mental illness, especially cultural variations in prevalence? How do cultural factors generate mental illness? What is the relation between mental illness and general psychology? What are the politics of culture that contribute to mental illness? In what ways is mental illness political? In what ways is the diagnosis and treatment of mental illness political?

In general, cross-cultural psychologists and psychological anthropologists have no cultural theory, psychological theory, or culturalpsychological theory. They have no concept of what the dominant cultural factors are which shape the features of other cultural factors, and what the interrelationship of cultural factors is like.

The lack of cultural theory and cultural explanation of mental illness is why specific cultural factors are rarely identified. Instead, symptoms are simply correlated with country names: "Russians have X kind of symptoms while Brazilians have Y symptoms.” This generality absolves specific macro 
cultural factors of responsibility for psychological disturbance. To describe Russian symptoms in detail (e.g., the meaning and character of anger or depression) is important in itself, however it provides no explanation about what generates psychological disturbance (how people are treated), how it does so, and what needs to be changed. Mere description accepts the given as it stands, de facto.

Cross-cultural psychologists and psychological anthropologists also construe culture as abstract variables such as "collectivism." These have no concrete origins, social structure, or politics (Ratner, 2011a, e; Ratner, 2012b; Ratner \& Hui, 2003).

Cross-cultural psychologists and psychological anthropologists generally adopt an apolitical view of culture and psychological phenomena. They rarely identify political features of culture such as alienation, tyranny, depersonalization, class structure, exploitation, commodification, gender oppression, ideology, or religious or political coercion in the concrete way that the Kleinmans do. They rarely use psychological disturbances and deficiencies to evaluate cultural factors and critique their deleterious politics (politics of disaster). On the contrary, they are generally reluctant to engage in any type of "outsider culture bashing" that might detract from a relativist appreciation of the social construction of differences. This concern limits many researchers to simply describing cultural and psychological differences without analyzing them - a strategy that is most welcome by oppressors who thereby escape criticism.

This avoiding of concrete, political cultural features blunts understanding mental illness and eradicating its sources. 


\section{A Macro Cultural Psychological Analysis of Saudi Psychological Disturbance}

We will now utilize our model to understand Saudi psychological disturbance. This entails first describing pathological normative cultural factors and psychology because they are the seeds from which disturbance grows. (We recognize that our typology is an ideal type in Weber's sense: selective, incomplete and idealized for the purpose of identifying essential common elements). We then examine ways that negative elements of normal culture, family, and psychology become concentrated and intensified in disturbed families and psychology.

\section{Pathological Normal Elements of Saudi Culture}

Like other societies, Saudi Arabia is plagued with a number of pathological normative elements. We shall focus on one evident element that we can trace in some detail to psychological disturbance. It is the distinctive pattern of gender relations that must be called "gender apartheid." This relationship entails the subordination of women. Of course, gender apartheid did not just happen, nor did it emerge from personal desires of individual men and women that were negotiated interpersonally. Gender apartheid in Saudi Arabia, including the exclusion of women from most areas of civil life, was imposed by the extreme, conservative, autocratic Wahhabi Islamic authority that was invited by the royal family to share political power in the 1970s in exchange for supporting the ruling family. The royal family has spent $\$ 100$ billion promoting Wahhabi Islam throughout the mid-East, including building Islamic universities. Exploring this theocratic-state relationship is outside the bounds of our discussion (see Ratner, 2012b), however it bears directly on gender apartheid, psychopathology, and numerous other social-psychological 
problems.

\section{Oppression of Women}

The Wahhabis have imposed strict gender apartheid and discrimination against women. This is promulgated through institutional rules, cultural concepts, and artifacts.

Gender segregation laws prohibit unrelated men and women from having any contact with each other. They attend separate schools and have separate friends. Women are segregated in banks (women go to the women's section, staffed with only women), hospitals, restaurants (women-only seating areas, and family- only seating areas segregated from areas where unaccompanied men eat), in lines waiting to be served fast food in shopping malls (when the first author inadvertently stood in the women's line, he was told to move), at the zoo and at fairs (men attend on certain days, women on other days). Even Imam university library has 1 day per week (a weekend day) for female students, and 5 days for males. University instruction is strictly segregated by gender. When male instructors teach female students they can never have personal contact. Instruction is via camcorder and telephone. Professors who have female PhD students spend five years working with them on their theses without ever meeting them. (Women are free to discuss prices of food and perfume and underwear with male sales clerks in stores, but they are prohibited from meeting a male professor to discuss their academic work!) Women are segregated at the beach by a wall so they cannot be seen by men. Islamic police patrol shopping malls and restaurants to break up contact between unrelated men and women.

Women's full-body covering in somber black robes and veils - while in public - enforces this gender apartheid. It depersonalizes them, prevents 
physical expression, inhibits most physical activities (including drinking coffee in public, which requires holding up the niqab with one hand and slipping the cup under it while it drapes down all around the cup and mouth, making drinking extremely awkward), and isolates them from interaction with men.

If a man brings a friend to his home, the friend never sees the wife or children. The house is structured so that the man and his friends have a space that is separated from the family space. If the man and friends are to eat a meal in the house, the wife prepares it before hand and leaves it for them without meeting them. Gender is distinctly spatialized. (The upper class is not bound by these restrictions. At home, royal class women freely interact with male outsiders without veils. They sit in large sitting rooms entertaining male guests. They vacation in Dubai where they drive cars with Saudi license plates.)

Consequently, a man's relationship with his friends takes him away from his family. He cannot do both at the same time. His friendships reduce his time spent with wife and children. This means that, between work and friendships, men spend relatively little time with their families. (Of course, there are quantitative variations on this common theme.)

The segregation of women is called haramlik, which means privacy and exclusion. The separate world of men is called salamled, which means inclusions, or welcome. Thus, men's world is open to inviting male friends inside, but women's world is closed to outsiders.

Government laws restrict women's freedom of mobility and bind them geographically - e.g., by prohibiting women from traveling abroad alone and driving cars.

Women are prohibited from working at most jobs. Women are only $15 \%$ of the work force. 
A cultural concept that bears on behavior/psychology is one of Prophet Mohamed's sayings that a man should never let his wife be alone with his own brother, because he can never be sure that some illicit relation will not develop. This Islamic cultural percept embodies and sanctifies the view that sex is an uncontrollable impulse that warrants suspicion and gender separation. It is believed by millions of men and women, including university psychology professors. It is enforced by the rule that when the husband's brother comes to visit his family, his wife must cover herself in his presence, just as she does with outsiders. These are important examples of the macro cultural psychological principle that macro cultural factors are loci of emotional formation, objectification, and socialization. The politics of macro cultural factors also imbue psychological constructs with politics. ${ }^{4}$

The oppression of women is also deleterious to men. Men have little knowledge of the opposite sex, they have no enjoyment interacting with women, except for their immediate families; men cannot know the families of their friends. Divorce is common. $40 \%$ or more of marriages end in divorce, most in the first two years of marriage. Women and men can both request

4 Saudi Islam says that interaction between males and females is an invitation to lust which lurks uncontrollably in the minds of everyone, ready to wreck havoc in society. This is the stated reason that the two genders must be separated. In other words, a psychological tendency is believed to be the basis of social laws.

Of course, this Islamic theory of sex is false. This false psychological construct (sex is lascivious) masks/rationalizes the real reason for gender apartheid which is political - to possess, dominate, restrict, and marginalize women. The specious Islamic psychology of sex enables authorities to say, "We are not restricting women, we are protecting them from dangerous sexual impulses." This converts political oppression into ostensible protection. This is how politics can distort psychological theory and psychological constructs.

Western psychological constructs may serve the same obfuscating, legitimating, mystifying political function. Constructs presuming the natural, inherited, cognitive inferiority of women and minorities are fictitious constructs that convert political-economic racism and sexism into the supposed by-product of cognitive and motivational inferiority of women and minorities. Naturalistic theories of mental illness similarly convert a social problem of social distress into a natural, individual problem of biochemical deficits. This psychologizing of political-cultural phenomena obfuscates their origins and prevents changing them. 
divorce. If a woman requests it, she must refund her dowry (approximately $\$ 20,000$ USD) to her husband. If the husband requests divorce, she keeps the dowry. Divorced women are often stigmatized. They are not virgins and have difficulty remarrying. They often use their children as surrogate partners for psychological intimacy.

\section{Pathological Features of Normative Saudi Family Structure}

The psychopathy of everyday life includes family relations. Far from the family being a haven in a heartless world, in fact it reflects and reproduces the heartless world just as education, religion, medicine, and psychotherapy do. Forces at large - consumerism, neoliberalism, progressivism, Islam - struggle mightily to influence family relations in their image. The family is as cultural and political as any social institution. Of course, each social sector has its distinctive features which refract other sectors in particular ways. However, all of them are subject to the pressures of the heartless world, including its pathological normalcy. Because the family is a seat of psychological disturbance, it is vital to have a full account of the family, including its pathological normalcy.

We obtained information about the Saudi family from interviews in two classes of Saudi male students at Imam University, Riyadh about their families. We used interviews to see how the macro factors map onto family experience. Cultural psychologists emphasize that people are active participants in culture, and their activity/agency mediates structural aspects of macro cultural factors. Just how it does so, and what the mapping of macro cultural factors onto individual behavior/psychology is, are empirical questions. We must see social structure as lived in order to gauge its effect on behavior and psychology. For instance, we must see what the actual social 
and psychological effects are of gender segregation, we cannot assume them.

One class of psychology sophomores was interviewed several times in April and May 2011 by Prof. Badwi (the instructor of the class) and Dr. Ratner, a visiting professor in the department for eight months. Other interviews were conducted a month earlier by Dr. Badwi with senior psychology students.

The students were happy to discuss their family interactions. They participated in the discussion actively and enthusiastically. Many students spoke up who had never talked in class before. While some social scientists might object that a group discussion would inhibit expression of true feelings because of embarrassment, or (implicit) group pressure - the opposite was the case. Students were drawn out of their reticence by the active conversational environment, and were quite eager to talk about their family patterns and those of their friends. They freely expressed variation in personal experience, but no disapproval. Of course, this group interview needs to be refined through other procedures, however both psychologists felt that it elicited genuine experiences. Indeed, as a first step, the group discussion appeared to be a much more comfortable setting for inciting personal discussion than private discussion - which would leave the isolated individual confronting a strange situation with no social encouragement or modeling. (This group-frankness may be culturally specific to Saudi Arabia, and may not apply in individualistic societies such as the United States. This would demonstrate that social science methodology -- as well as cultural theories -- must be culturally sensitive.)

The students were frank in their discussion to the point that they acknowledged having girlfriends of which their parents were unaware. This is a major social change because the current repressive Islamic authority in Saudi Arabia forbids contact among unrelated males and females. Yet these boys meet girls on the internet, call on the phone, and then meet in secret. This meeting takes amusing forms. One is for girls to ask their family drivers to 
drive them to a mall and wait for them a few hours, whereupon they disappear and sneak into their boyfriends' car. A most inventive ruse is for boys to dress up in a woman's abaya (black robe) and full facial veil with only eye slits, enter the girl's house disguised as a girlfriend, and then follow her into her room! It is sweet irony that the garb that is designed to segregate women from men is used to subvert the system and enable girls to have intimate relations with boys. The anonymity and invisibility that is supposed to render girls immune to men's contact is ironically adopted by boys who use it to enter girls' space and have personal relations with them. ${ }^{5}$

There were numerous common family experiences that the students agreed to. This indicates there are normative family patterns. (Idiosyncratic responses are not included in this summary because we were looking for normative family patterns.)

Both authors framed specific questions to the class to answer. These included, "describe the relation between your mother and father," "describe your relationship with your sister(s)," "when your father disagrees with you do you feel resentful?" "have you ever seen your parents kiss, hug, or hold hands?" "was your father always strict with you?" Our questions elicited animated responses. When individuals reported different experiences, we asked "how many of you had this experience, or that experience?" We were probing for general, shared experiences that indicated normative patterns. Only responses that commanded general (not universal) agreement were included in our report. We do not cite precise frequencies because the

\footnotetext{
5 This is akin to blacks and whites circumventing racial apartheid laws and becoming friends.

When the students resist certain Islamic rules prohibiting contact with girls, their resistance is fostered by emerging alternative cultural norms of American consumerism, sensationalism, hedonism, and individualism that are displayed in ubiquitous television programs, video games, music, shopping malls, and visits abroad. Resistance to Islamic controls is not a personal construction.
} 
generally shared experiences encompassed the vast majority of students. This satisfied our quest for normative patterns. We did not need precise numbers or unanimity to establish norms. We did not feel comfortable counting hands, as this would have artificially interrupted and formalized the animated flow of the discussion.

\section{Normative Saudi Family}

The normative family pattern that emerged from the two class interviews contained the following distressing and fulfilling elements (we reiterate that these do not exhaust the characteristics of Saudi family life):

- Authoritarian, fearsome father.

- Father not visibly intimate with children or wife: no kissing or touching. Not one student had ever seen his parents touch or kiss or hold hands. Nor do fathers or mothers hug and hold their children (not including infants). Nor do brothers and sisters touch, except for some playful pushing and shoving.

- Father and mother are generally critical and negative toward son, not positive about his successes.

- Father not empathic with children.

- Father externally oriented toward friends and business, not interested in children, school, etc. Little time with family. As fathers age, they spend more time at home.

- Many husbands and wives talk intimately about family matters, relatives, personal gossip. One topic of concern is soliciting potential spouses for their children. They go on vacations together and sometimes shop together, visit restaurants together. Younger couples can be seen holding hands on the street. Couples joke around. 
- The family is defined by father's name and status.

- Father wants household centered around his needs and desires. But he has little actual authority because he is outside the home so much. He is an emperor without an empire, so to speak.

- Mothers tend to resent fathers' physical and psychological distance from family; resent his authoritarianism. But also support and respect him. Ambivalent relation.

- Father transfers authoritarianism to school principal and teachers. Wants them to be authoritarian, condones physical punishment. He uses Saudi phrase: "You take the fish and give me the bones."

- Fathers are more attentive to and accepting of children as they mature. Father also spends more time at home. Consequently, sons interact more with him during adolescence and turn to him for advice and permission.

- Children are closer to mother than father because of the structural separation between father and family. Children call their mother and their grandmother by the same word "mom." At the same time, the father's name and status define the family. Children think of themselves as belonging to their father's family, although they are closer to their mothers. This can generate some psychological ambiguity and conflict.

- Mother is subordinate to her mother in relation to children. The grandmother's word is more powerful than the mother's.

- Mother is submissive to father. Does what he wants.

- Mother is adored by children. When asked "what is the best thing you like about your mother?" all the students said "everything." No complaints at all. She makes them happy, accepts a lot of what they say, they can convince her of their opinions and desires. She tries to 
explain to her husband what the children need and how they think so that he will do what they wish.

- When asked "What is the best thing about your father?" students were reserved; they said "he advises us about right and wrong behavior."

- Mother instructs children to be passive and quiet and unobtrusive in public. Do not speak or display intelligence.

- Average family size is 6 children.

- Housing is designed as insulated structure. Small windows, high walls. Insulated from world. The family is the only place where all the members can freely interact without physical separation of veils and separate rooms. As soon as anyone outside the nuclear family enters the house, the women must cover up and not be alone with a visiting male, or even seen by a male who is not related by blood. Ironically, the family's very exclusivity undermines its intimacy; because men and women must keep their friendships separate from the exclusive family, this draws husbands and wives apart.

- Eldest brother is domineering and reflects father.

- Brothers always dominate sisters, even when sisters are older. Mother encourages this. Tells sisters to listen to their brothers, and tells brothers to protect sisters.

- Mother takes the salary from father and spends on household. Father isn't happy and often lies about his salary to keep part for himself.

- Husbands and wives often argue.

- Often argue about money and consumer goods. Wives demand more consumer goods from husbands which husbands may resent

- Children must obey fathers. They cannot disagree if they know 
that it will anger him. Often suppress desires or opinions for fear of annoying father. Consequently, fathers do not fully understand their children. Children may express an opinion but if they see the father is unhappy about it they withdraw. If they challenge him, he occasionally slaps them with objects that cause pain.

- Fathers rarely admit they are wrong. At best, they remain silent if they agree with their children's discrepant opinion. But this rarely happens because children are intimidated into not arguing. As they become more mature, children do express their opinions politely, but fathers always have the last word.

- Children often turn to mothers to express desires and opinions and hope mothers can convey to fathers.

- Women have strong ties to their mothers, siblings, and female friends.

- Interpersonal relations among men are similarly quite friendly, humorous, generous, and dependable. They provide a great deal of fulfillment in a society that segregates them from women.

- Contemporary Saudis come from tribes which retain close ties despite being dispersed across Saudi Arabia nowadays. Members of a tribe have annual meetings where 2,000 people get together -- each gender in its own compound.

- Many women are unhappy about the restrictive rules that are imposed on them.

- These 19 year old students fully accept male-female social roles. Most want wives who are submissive and make them happy without argument. A few want more companionate marriages. All the boys believe it is their right to dominate their wives and control them. All agreed that they have the right to tell her how completely to cover 
her face in public -- full cover with eye slits, or more revealing of the face. Their wives must obey their decision. All the boys want their future wives fully covered so no other man can see them. They desire full and exclusive possession of their wives ("she is all mine"). They are jealous of other men and possible attraction. All the students said they would not marry a girl who refused to cover up. All also believed that they have the right to control how much time the wife spends outside the home shopping or seeing friends. If they don't like her shopping, they will restrict her to the home 6 days per week. The students were quite adamant about their authority. It is a takenfor-granted assumption without question or hesitation. (These acts of possessing women as the man's property are reinforced by the Islamic sexual myth that we discussed in footnote 5.).

- None of them had heard of a female who disliked covering up. They said girls and women accept it as the standard.

- When asked, "Would you prefer to have more contact with girls, e.g., in class, in the library, chatting in malls?" not one said yes. All said they don't want more contact because it would be distracting and they would fail in school. Every one of them has accepted gender apartheid. ${ }^{6}$

These subjective reports of students' family life are isomorphic with structural macro cultural factors described earlier. Both the objective and subjective data testify to a general (not universal) pattern of estrangement and

6 These are young, contemporary, college educated boys - the future of Saudi Arabia -- living in the 21 st century amidst Arabic social revolutions, women's liberation, and human rights struggles; yet they never consider these as applicable to their lives. The concentrated ideology and social structure in which they live blunt considering these external models as a basis for reconsidering their treatment of women. Even when young men and women meet secretly against their parents' wishes this does not lead to new gender relations, as these college students unanimously testify. 
conflict between husbands and wives, and fathers and children.

This triangulation is a valuable contribution to cultural psychology, and social theory. A major question about structural analyses of society is whether they describe the lived reality of people's behavior and psychology. Our research demonstrates that structural analyses do pertain to subjective experience; they provide insight into experience, and explain experience. This conclusion has important methodological and theoretical implications. It means we need to understand structure to understand experience; and it means that we should formulate empirical research into subjectivity around structural issues, to probe structural issues in relation to subjectivity, as a source of subjectivity.

The existence of a common family structure logically implies broader macro cultural factors that generate it in concert. Families are independent of each other and do not meet to decide on a common structure. The fact that families independently arrive at a similar structure proves that they are subject to centralized, common higher level factors which orient them toward a common form. Bronfenbrenner's model (1979) of a set of concentric circles, with macro cultural factors composing the outer ring and structuring the inner circles in a common manner depicts this well.

The negative aspects of Saudi culture and family affect men and boys as well as women and girls. Saudi men are often estranged from their wives and children, they are often placed in ambivalent roles (provider and authority vs. distant and uninvolved), and they often suffer psychological stress as a result of the apartheid that is designed for and practiced on women. Oppressing and discriminating against women takes its toll on men as well. In normative Saudi families, negative elements are modulated and mitigated by positive aspects of Saudi culture. These include strong ties among women to their mothers, siblings, and friends. Interpersonal relations among men are similarly quite friendly, humorous, generous, and dependable. 
Certain individuals have the misfortune to encounter negative cultural elements in large doses without compensatory, protective, positive elements. One reason might be their relations with family and friends are frayed. In addition, fundamentalist Wahhabi Islam has intensified negative family aspects by exacerbating the distance between husbands and wives. These individual and social pressures for intensifying oppressive, estranged social relations in the family, foster disturbed psychology.

\section{A Disturbed Family Structure in Saudi Arabia that Generates Mental Disturbance}

One pattern of disturbed family structure (not the only pattern) that generates psychological disturbance in Saudi Arabia is what we call the ambivalent family structure. It involves ambivalence in the roles of husbands, wives, and children. Dr. El-Badwi identified this family structure from his patients' reports.

\section{Ambivalent husbands}

On the one hand, the husband is the head of the household, the bread winner, the authority figure, and his name and status define the family.

Despite this picture of authority, the husband has little real authority in this home. Major decisions about family life are made by the wife. The husband comes home, flaunts a domineering image, bestows money on the family, and then exits, without having exercised real dominance. Then his wife takes over and makes family decisions and has the major influence over her children.

The man is typically the breadwinner. He gives money to his wife. Often, he does not tell her the full amount of his salary, and keeps part for his 
own use. The wife controls daily expenditures of money, since the husband is away at work or out with friends. The husband is often resentful because he brings in money, is told it has been spent, and is not enough, but he has no control over it or knowledge about it.

\section{$\underline{\text { Ambivalent wives }}$}

In the ambivalent pattern, the wife is deferential to the husband when he is present. She instructs her children they must be similarly deferential and respectful. However, she also resents her distant, authoritarian husband and complains about him.

\section{Ambivalent children}

Children internalize ambivalent feelings about parents and gender roles. They become ambivalent about their own gender role and self.

\section{$\underline{\text { In-grown relations }}$}

In this disturbed family structure, the wife compensates for her solitude and resentment by depending upon her children for closeness and affection. She spoils them and overprotects them. This leads to tying them to her and the family. It incapacitates them from having close relations with others outside the family.

If these children marry, they remain psychologically tied to their mothers. This prevents them from establishing a close relationship with their spouses.

Men, in particular, become infantilized and feminized through their psychological ties to their mothers in ambivalent families. They often wish to be men as their respected fathers are; yet they have been pushed away by their fathers, seen them powerless in the family, and they become controlled by and 
attached to their mothers. This creates ambivalence in their sexual identity, which tilts toward the feminine side.

The disturbed family as variant of the normative family

The disturbed ambivalent family pattern has clear ties to the normative family structure and broader macro cultural factors. The ambivalent socialpsychology of the father, mother, and children are exaggerations of normal ambiguity of gender and children roles, distant gender relations, distant, distracted fathers/husbands, solitary wives alone with children, respectful yet resentful wives, dutiful yet resentful husbands, and respectful children who cannot express themselves to fathers, remain psychologically distant from them, and become psychologically tied to their mothers.

The ambivalent family structure is not normative, but neither is it idiosyncratic, unrelated to the culture. On the contrary, it is facilitated by the culture; it is composed of negative elements of normative culture that congeal in a concentrated package, without amelioration by the culture's positive elements. This is why the disturbed Saudi family and its associated psychopathology is a distinctively Saudi phenomenon. Certain elements may overlap in different societies, however the system of elements, and the full quality/significance of each are different.

\section{Macro Cultural Psychology of Saudi Psychological Disturbance: A Case}

\section{In Point}

Now we investigate how deleterious elements of disturbed families exaggerate socially patterned defects to generate individual psychological disturbance. This case study comes from Dr. El-Badwi's patient, Faisal.

Faisal is a 25-year old obsessive-compulsive. He has a university degree, and 
is a high school teacher. He became engaged in an arranged marriage two years ago. But he cannot accept the idea of marriage and is obsessed with thoughts of divorce, i.e., cancelling the wedding. His obsession leads to guilt feelings that he is opposing his parents' arrangement. He engages in numerous rituals to distract himself from thinking of divorce. One of these is frequent prayer that helps atone for his sinful thoughts of divorce. However, he cannot help thinking about divorce. This makes him feel his prayer is insincere, so he prays more ritualistically. He is so distraught by this cycle that he pays for 3 therapy sessions a week.

Faisal's presenting symptoms emanate from his disturbed family background. Faisal's parents divorced when he was 4 . He never knew his father but he heard terrible things about him from his mother. His mother slept in the same bed with him, holding hands, until he was 18 . She spoiled him and overprotected him. She insisted that he bring his friends home to play and not go to their houses.

His mother's overprotectiveness was tinged with restrictive control, intimacy, demand for excellence, paranoia about a dangerous world, and threats - e.g., she asked god to destroy Faisal if he failed to obey her demands. Faisal's mother's treatment of him stemmed from her precarious role as a divorced, stigmatized woman in Saudi society. She was vulnerable because she lacked a male protector, lacked a means for supporting herself, lacked a way to be productive in society and achieve self-esteem. This normative pathological and pathogenic social reality made her feel she had to

- desperately push him to become the male figure in the family, by demanding and threatening him. He felt she was using him as a weapon in her paranoid fight with the world. He confessed in therapy, "I am her gun."

- attach him to her so she could rely on him for psychological 
intimacy to compensate for a lack of other sources;

- (over)protect him from the social dangers she perceived;

- strive to help him succeed in this hostile environment by directing and demanding him to act, and frightening and threatening him when he did not.

Her needs, desires, emotions, perceptions, self-concept, and concerns were shaped by, characteristic of, and functional for the vulnerable social position of a divorced Saudi woman that is worsened in a disturbed family pattern. They are not idiosyncratic quirks of her personality.

Her overprotective love for Faisal is a culturally specific form of overprotection consisting of a particular constellation of elements; it is not a general, abstract overprotection that is equivalent to all other instances of overprotection in other cultures. Other forms do not necessarily involve paranoia, vulnerability, violent threats, intimacy, dependency, strict demands/ control, ambivalence, and using children as weapons in their fight against the world. For example, a middle class American mother may overprotect and over-direct her child to do well in school to further his upper middle class career and follow the family's privileged tradition. This overprotection would have the objective of maximizing the self-fulfillment of the child; it would not aim at resolving the vulnerability, anxiety, ambivalence, and dependency of a vulnerable, precarious mother.

Faisal's family was a cauldron of ambivalence. His mother vacillated between intimacy with him and violent threats, requiring success yet stifling him with restrictive demands, being a man ("the man") yet feminizing him. She presented herself in ambivalent ways, and she treated him in ambivalent ways. Likewise, she criticized his father as disinterested, cruel, and dangerous, but when Faisal needed help for some problem - e.g., money, medicine she called upon his father to support him. Faisal confessed to Dr. El-Badwi 
that he didn't understand his mother's attitude toward his father. This became recapitulated in his own attitude toward his father.

This ambivalence is an intensification of the normal ambivalence that is built into the structural family role of Saudi men and women.

The mother's normatively-derived disturbed psychology (her psychology of oppression) placed Faisal in untenable situations that disturbed his psychology.

The contradiction of protectiveness/spoiling with threats, fear, and demands left Faisal confused and ambivalent about his mother, father, and himself - did she love or hate him, should he love or fear her, was he good or bad? He became confused about male and female gender roles as well.

The disturbed family structure made him so attached to his mother and sisters that he could not separate from them to form an intimate relationship with an outside partner. His intimate desires focused on his sisters because they were part of his intimate, familiar, protected comfort zone. His only outside interests were self-defeating, unrealizable, casual, degraded homosexual encounters which would never threaten his incestuous preoccupation with his female family members.

When he was 11 , he secretly became a promiscuous homosexual. He played a passive, submissive role in these encounters. At 16, he became enamored of his sisters; he developed sexual thoughts about them and tried to see them naked.

He became profoundly guilty about these sins. He tried to atone for them by compulsively praying. He alternated helplessly between the illicit acts/thoughts and praying.

His passive position in homosexual encounters reflected his passive position in relation to his domineering mother and the authoritarian, hateful image he had of his father. 
Faisal's responses to the TAT test, administered by Dr. El-Badwi, expressed approach-avoidance conflicts, uncertainty, hesitation, lack of cohesive groups/families, interpersonal conflict, suicide, malicious women (card \#5), a man who challenged his mother and was later destroyed (card \#6), a passive young man whose life was destroyed by an older man (card \#7), a child searching for his mother to no avail (card \# 11).

All of this precipitated Faisal's presenting symptoms - his dread of marriage and his obsessive-compulsive praying. When Faisal's parents arranged for him to become engaged, he could not refuse, but neither could he accept it because it would tear him away from his mother and sisters. The engagement threw him into an approach-avoidance oscillation that he tried to resolve through asking Allah for guidance and forgiveness. However, prayer proved incapable of resolving the deep social-psychological conflict his mother had generated. In fact, there is reason to believe that the Islamic prayer routine exacerbated Faisal's distress.

Wahhabi Islam is itself is a form of compulsion that imposes its theocratic rules throughout Saudi life. All Saudi Muslims are compelled to cease their activities, close their businesses, and pray five times a day. Clinicians have observed that this kind of extreme religiosity generates severe guilt. A syndrome has been coined, known as "scrupulosity." Scrupulosity is an obsessive concern with one's own sins and compulsive performance of religious devotion. It is personally distressing and often accompanied by impairment in social functioning. Steketee, Quay and Whilte (1991) explained that the more religious a patient, the more likely he or she was to complain of religious obsessions. Several historical and religious figures suffered from doubts of sin. Loyola, the founder of the Jesuits, is one example. Scrupulosity's first known public description as a disorder was in 1691, by John Moore who called it "religious melancholy" and said it made people "fear that what they 
do, is so defective and unfit to be presented unto God, that he will not accept it." Scrupulosity can affect any devoutly religious denomination (Inozu, Clark \& Karanci, 2011; Yoriulmaz, Gencoz \& Woody, 2010).

In our model of psychological disturbance, scrupulosity may be considered to be pathological normalcy. It generates distress through its normal religious rituals, and when scrupulosity becomes intensified it can lead to severe obsessive-compulsive symptoms. This occurs for individual reasons and social reasons. Individual reasons include disturbing personal events that drive individuals to more devout praying, such as Faisal's case. Individual reasons also include parents or teachers leading individuals to intense scrupulosity because of their personal convictions. Scrupulosity also becomes intensified when social leaders introduce more intense scrupulosity into religious practices, as the Wahhabis did. Then everyone who practices it will be subjected to exaggerated guilt and obsession.

We propose that Faisal's OCD was intensified by the scrupulosity he used to relieve his conflicts. Macro cultural psychology maintains that cultural factors such as Islam contain psychological elements which are transmitted to users of those cultural factors. When Faisal delved into prayer as a way to relieve his conflicts, he exposed himself more thoroughly to Islam's punitive tenets. These made him feel more guilty about his behavior and drove him to pray even more compulsively. Fundamentalist Islamic religious doctrine intensified Faisal's OCD, it was not merely a tool he used to express his existing OCD.

This observation is supported by research into the link between scrupulosity and OCD. Freud, in 1907, described obsessional neurosis as an ‘individual religion' and religion as 'a universal obsessional neurosis'. While the second phrase is an overstatement, extreme features of religion such as strict piety may become exaggerated into pathology. This may occur for 
personal reasons, such as stress, driving an individual to subsume himself more completely in scrupulosity; it may also occur for social reasons as leaders of a religion make it more demanding and punitive for all practitioners. Scrupulosity seems to be the normal pathology that morphs (metastasizes) into pathological OCD. This means that devout religion predisposes people to OCD, just as gender apartheid predisposes gender social-psychological estrangement. Devout religion does not simply contribute religious content to mental disorder; it predisposes people to disorder. Sica, Novara and Sanavio (2002) found a higher incidence of obsessive-compulsive disorder among people who are exposed to devout religion. Abramowitz, Deacon, Woods and Tolin (2004) reported a link between religiosity and cognitive biases that are thought to increase the risk of developing OCD. Okasha, et al. (1994, p. 191) reports that "The role of religious upbringing has been evident in the phenomenology of OCD in Egypt, which is similar to the outcomes of studies in Jerusalem."

This is clearly the case with Faisal. It testifies to the principle of macro cultural psychology that cultural factors shape and induce individual psychology by transmitting socially-constructed psychology and behavior that are embodied/objectified/incarnated in macro cultural factors.

\section{Psychopathology and Society}

This case illustrates the macro cultural psychological model of pathology: the continuity between individual psychology, the family, and culture. We are able to explain Faisal's psychological disturbances (as well as his mothers') in social terms without postulating non-social mechanisms such as psychoanalytic or personal or bio-chemical ones. We have been sensitive to complex psychological dynamics and concerted individual activity to make 
sense of things and find solutions to problems within the rubric of macro cultural psychology. The complex dynamics between Faisal, his mother, his sisters, his homosexual partners, his self-doubts about identity, his confusion about his parents, his conflict over marriage, and his compulsive praying are all intelligible outcomes of cultural structures. These structures led him to be treated in certain ways, and to interpret and respond to this treatment in certain ways - with guilt, praying, ambivalence, self-doubt, effeminateness, and submission to authority. This situation parallels the cultural structuring of Chinese psychological disturbance that the Kleinmans described earlier.

Faisal "totalized" Saudi cultural structures (e.g., family structure, religious structure, marital system), stressors (repression, anxiety, apathy, ambivalence, estrangement) and belief systems (about what qualifies one as a good child, male, mother, father, and Muslim) to generate a set of psychological disturbances. He did not personally invent his psychopathology.

Because Faisal's psychological disturbance incarnates cultural elements, it is similar in many ways to other cases of Saudi psychopathology which are also rooted in general, normative cultural factors and their derivatives (Ratner, 1991, chap. 6; Ratner, 2011b).

Of course, culture does not provide every single aspect of Faisal's psychology. It does not instruct him to become a promiscuous, passive homosexual. However, culture structures his life space in such a way that it leads to this form of behavior. Faisal could have chosen other specific behaviors but they would all have had to embody the same ambiguity of selfconcept, low self esteem, feminization, and inability to threaten his maternal ties that his cultural history generated. His choice was framed by these cultural parameters.

It is noteworthy that the culturally-induced social-psychological problems which Faisal experienced impaired his ability to fulfill many cultural 
prescriptions such as marriage. This is an example of social contradiction: the norms are so pathological that they undermine themselves in certain cases. This is the case with all anti-social behavior. It is ultimately induced by cultural norms and undermines cultural norms.

\section{Agency}

The case of Faisal illustrates the active role that agency plays in constructing creative solutions to untenable social-psychological dilemmas, but in ways that respect the constraints of those imposed dilemmas and never truly overcome them. For instance, he sought to fulfill his need for outside relations in ways that would not threaten his incestuous family relation. He also sought to maintain his familiar subordinate social position in these relations. He actively did all this in creative ways that preserved the social constraints which had been imposed on him. His activity did not transcend, negotiate, or negate these constraints. Faisal did contradict societal norms of marriage, however not because he personally negotiated them; rather, because his disturbed family made him incapable of fulfilling them. This confirms Leontiev's and Vygotskyi's observation that personal meanings are expressions of culture.

Sartre devoted his book Search for A Method to explicating this dialectic between individual agency and society. He explains how "The worker projects himself toward his own self-objectification in terms of material, historical conditions." Similarly, "It is inside the particularity of a history, through the peculiar contradictions of this family, that Gustave Flaubert unwittingly served his class apprenticeship" (Sartre, 1963). Sartre emphasizes that choices and projects incarnate and fulfill cultural frameworks. Subjective activity "totalizes" or draws together cultural elements - structures, stressors, beliefs, prohibitions, conflicts, ideals -- into a psychological resultant or 
derivative. This leaves psychological phenomena active but informed by cultural factors.

Sartre sought to capture the relationship between individual lives and group patterns with a "progressive-regressive method": the progressive method apprehends the movement of the individual from the whole to create his particular life-project, while the regressive method situates the individual back into the whole (group).

Creative agency did not enable Faisal to break the bonds of his culturalpsychological problems. Creativity can take all sorts of fanciful, illusory, superficial, trivial, irrational, dangerous, harmful forms that do not liberate one from social-psychological constraints. Only creativity that comprehends a problem and how to concretely overcome it is liberating creativity. Creativity, in other words, is compatible with social constraints and conformity. It is only incompatible with them when it takes certain specific forms. We must strive to identify these and not content ourselves with glorifying creativity abstractly, in general.

\section{Extending Macro Cultural Psychology to New Territories}

Our case study of mental illness in Saudi Arabia lends credence to the macro cultural psychology of mental illness that is based upon Vygotskyian concepts and other theoretical contributions. It is gratifying to see that the model is potentially applicable to Saudi Arabia and other societies. This would qualify macro cultural psychology as a general theory of mental illness throughout diverse cultures.

Adding a viable, general theory of mental illness to the arsenal of macro cultural psychological explanatory constructs, would also qualify macro cultural psychology as a general, comprehensive psychological theory of all 
psychological phenomena - mental illness as well as perception, cognition, emotion, developmental processes, personality/self, and memory. This would fulfill the criterion for making macro cultural psychology a scientific paradigm, for it would explain the totality of psychological phenomena everywhere by a parsimonious set of logically consistent constructs.

\section{The Politics of Mental Illness, Macro Cultural Psychology, and Other Theories of Mental Disturbance}

Our research into mental illness reveals an important political dimension of mental illness and psychological theories about it. Disturbed family and psychology (can, given the proper theoretical explanation) reveal the negative elements of normative culture that are typically modulated and camouflaged by positive elements. Deleterious psychological phenomena have a radical potential to indict normative culture and call for its improvement through transformation.

If negative macro cultural elements are pathogens that foster social and psychological pathology, then normal macro cultural factors must be radically transformed in order to eradicate the origins of social and psychological disturbance, and to make social and psychological activity fulfilling. We must develop new normal macro cultural factors, family structures, and psychology that are benign and will not readily metastasize into social and psychological pathology. The scientific study of mental illness thus leads to political critique and transformation of the status quo. Good science and good politics are intertwined.

Our psychological analysis of deleterious cultural factors compliments social critiques leveled by other social sciences. Sociologists, educators, political scientists, geographers, economists, and anthropologists will expose 
weaknesses in macro cultural factors from their particular positions. Cultural psychology compliments these by revealing the deleterious psychological effects of certain cultural factors. This is an important addition to social critique and improvement. Cultural factors are not only injurious to health, the environment, educational prowess; they are also injurious to psychological fulfillment. This is further grounds for improving cultural factors and further direction for how to do so.

While social critique and transformation are imperative for improving social life for the majority of the people, it threatens the powers that control society. This is why those powers - including the ideology that legitimates them - attempt to explain psychology, educational success, health, wealth, poverty, crime, and class structure in non-cultural terms (biological, individual, interpersonal) that do not implicate cultural factors.

Since deleterious behaviors and competencies such as mental illness, suicide, low IQ, low motivation, aggression, and criminality are the most damning indictments of cultural factors -- by exposing them to be causes of deleterious behavior -- it is imperative for the ruling interests of society to obscure the connection. It does so by treating psychological debilities and anti-social behavior as explained by biological, personal, and interpersonal processes rather than cultural processes. This is the primary basis of the acultural orientation in psychology. It then spreads beyond psychological debilities and anti-social behavior to psychology in general. Oppressive politics is thus the basis of bad psychological science.

Bad science and bad politics go hand in hand just as good science and good politics do. Each contributes to the other, is dependent on the other, and is an indicator of the other. Ignoring/denying/censoring pathological normalcy is the clearest indicator that social life is pathological. For ignoring/ denying pathological normalcy and censoring its exposure is the surest way 
to perpetuate it. A benevolent society would relish identifying its weaknesses so it could eradicate them and improve life. Humane and inhumane societies thus value different kinds of social science: one that scrutinizes macro cultural factors vs. one that obfuscates them, respectively. Social science is political in legitimating or critiquing the status quo; and the kind of social science that a society values is an indicator of its humaneness.

We must see pathology in normalcy in order to eradicate it from normalcy. We must see pathology as normal in order to make it abnormal (not part of normal social psychology). The more we think of pathology as intrinsically abnormal (extrinsic to normalcy), the more we overlook its normalcy, and the changes we must make in normal culture to make pathology abnormal.

We must see pathology as necessary to normal culture before we can make it accidental to culture. If we see it as currently accidental, then we will ignore its centrality and we will perpetuate it.

We must see pathology as social rather than individual before we can expel it from the social structure and relegate it individual idiosyncrasies. If we see pathology as intrinsically individual, we will ignore its social basis and allow it to fester; regarding pathology as individual will enable it to remain social.

Where other approaches to mental illness regard it as inherently individual, accidental, abnormal, and external to society, macro cultural psychology identifies pathology as intrinsic to the current social organization of normalcy. Therefore, we must transform normal social life in order to make pathology something that is actually, in the future, what people erroneously assume it is intrinsically like today - namely, extrinsic and anomalous to normal society, and due to individual deficiencies. Realizing the current assumptions about mental disturbance can only occur in a new future society. 


\section{Reconceptualizing Psychopathology: From Pathologizing Pathology to Normalizing Pathology}

Treating pathology as endemic to certain kinds of normalcy and as the outcome of normalcy radically transforms the conception of pathology and normalcy. Normal pathology makes normalcy less reasonable in the sense that it is not good for people, and it makes pathology more reasonable, in the sense that pathology is an understandable response to untenable conditions. For example, when a female victim of domestic violence retaliates by maiming or killing her husband, this does not make her act acceptable, but it makes it understandable and often absolves her of crime.

Pathological normalcy changes pathology from something outside the normal (anomalous) and opposed to the normal (anti-social), to something that reflects the pressure of the normal ("hyper normal"). It changes pathology from an individual phenomenon that is rooted in individual deficiency, to a social phenomenon. Pathological normalcy normalizes pathology, whereas the traditional conception of pathology pathologizes it as something foreign and anomalous to normalcy. ${ }^{7}$

Describing the pathology of normalcy is necessary for identifying the normalcy (normal roots and presence) of pathology. If we misconstrue normalcy as free from pathology, we will misconstrue pathology as independent of normalcy. And if we misconstrue pathology as independent of normalcy,

\footnotetext{
7 Indigenous psychologies tend to pathologize psychological disturbance as individual deficiencies in conforming to social norms. For example, Islamic psychology would explain mental illness as stemming from a) lack of faith in Islam, b) that allows evil thoughts to enter the mind, which c) lead to psychological disturbance. Islamic psychology supports the status quo by asserting that cultural concepts such as Islamic theology are key to personal salvation. Violating normative Islamic theology is assumed to impair people. Islamic psychology pathologizes psychological disturbance by attributing it to personal failures to conform to Islamic theology. Islamic analysis leaves no room for cultural causes of psychological disturbance, especially pathological normal cultural influences. Indigenous Islamic psychology is therefore not cultural psychology.
} 
we will misconstrue normalcy as free of pathology (which is the scientific error and legitimizing political function of psychiatry and psychology).

Normalizing pathology does not justify or idealize it as good. That's why we call it pathology (disturbance, illness). However, normalizing pathology makes it intelligible and points the most effective way to reduce it, by minimizing the conditions that generate it.

In contrast, pathologizing pathology prevents reducing it because its primary social causes are not addressed. Instead, treatment is confined to pathological individuals who are left by this approach to live under pathological conditions. ${ }^{8}$ Individual treatment in the face of perpetual assault has two characteristics: 1) it is inadequate; it is a pseudo solution that does not treat the root cause and only suppresses the symptoms; 2) it is temporary and therefore must be continued indefinitely. If it is stopped, the symptoms reappear in response to the persistent, unmitigated causes. ${ }^{\dagger}$

Normalizing pathology is an inherently critical, political intellectual act. It critiques the normal status quo as having abnormal elements that are deleterious and must be changed. Since the status quo is not truly normal, normal cannot be defined in terms of the status quo. Normal is not what exists, but rather what does not yet exist; normal is an ideal concept that must be brought into being. Normal is a two-dimensional term that transcends the status quo, it is not a one-dimensional recapitulation of the status quo. Normal is a critical term rather than a legitimating term; normal expresses an ideal sense of good rather than the real (existing) sense of good.

This ideal sense of normal is used to define physical health. Normal $=$ healthy or what is best for the body; it is not defined in terms of peoples'

8 Even cancer is a pathology that is pathologized rather than normalized by physicians. It is treated as caused by defective genes and family history, instead of acknowledging it as caused by normal politics and economics that generate pollution.

${ }^{\dagger}$ Check end notes. 
current physical state. Anything less than the ideal is abnormal, regardless of how prevalent it is. The fact that $2 / 3$ of Americans are overweight does not make it normal; it remains a state of abnormality vis-à-vis ideal normalcy, or what Americans can and should achieve. Medical normalcy is an ideal, futuristic, transcendent concept, and psychological normalcy is as well.

"Normal" presupposes an external view of what is fulfilling rather than a view that is circumscribed by and internal to how people currently live. (We have discussed the limitations of indigenous psychology throughout this article.) Normal offers a way out of the limited status quo; it is the great refusal (see Marcuse, 1964, 1987; Ratner 2011a, p. 134 for discussion of this dialectical concept).

This ideal, futuristic, transcendent sense of normal refuses to accept oppression and alienation - e.g., gender and racial apartheid - as normal, acceptable, or healthy.

All normative terms should be defined in terms of an ideal norm to be achieved rather than current practice. In Hegel's words, they should be defined negatively, as what they are not yet, rather than in positive terms of what they currently are. This transcendent, dialectical, ideal, futuristic, negative normativity is welcome because it offers us a direction to strive for that will improve our lives. We must discover what our normal - i.e., best, ideal, necessary, potential - state of psychological, social, and physical functioning can be in order to know how to fulfill ourselves - just as we must discover what our normal cholesterol and blood pressure levels are/should be/ can be in order to makes ourselves into prime physical condition. Defining normal in terms of the status quo, condemns us to its limitations. 


\section{Psychotherapy}

The macro cultural psychological analysis of mental illness also has important applications within individual psychotherapy. Dwairy and Van Sickle (1996) point out important therapeutic implications of the distinctive Arabic cultural psychology.

Given the self is an independent and differentiated entity in Western society, psychiatric problems have been conceptualized using a model which relies upon intrapsychic structures and dynamics. Consequently, interventions are designed to address internal psychological processes or conflicts, which are considered as comprising the roots of psychiatric illness.

As previously mentioned, differentiated personality and independent personality structures are not presently a feature of the Arabic person. Therefore, instead of personal explanations, social and cultural explanations of behavior are provided. Thus, agents of repression are both conceptualized and experienced as originating from external sources, specifically the family and society. Therefore intrapsychic conflict is secondary to interpersonal conflict. Western psychotherapy would appear to be better qualified to address intrapsychic conflicts rather than person-society conflicts. Therefore, conducting psychotherapy with an Arabic individual who suffers from repression maintained by external sources would appear to be 'digging in the wrong field,' as it is the symbiotic relationship with the family which must be addressed. Despite differences in theoretical orientation, a primary goal of Western psychotherapy 
is to enhance self-actualization and promote integration of the individual's personality. To achieve this, the therapist helps the client to become aware of repressed emotions and needs, and to learn how to appropriately express these needs and emotions. As a result, the individual's personality and behavior become more functional and integrated.

On the surface, behavior therapy would appear to be valuefree, suggesting that it will result in few cultural and/or social conflicts. However, the assertive coping models which it espouses would be considered provocative or rude within the context of traditional Arabic societies. Additionally, during the course of child behavior therapy, there is usually a point at which the therapist begins to direct the child in the use of behavioral management techniques to establish a new balance between the child's needs and the needs of the parents. These efforts may conflict with the traditional Arabic norms which emphasize a hierarchical family structure. The parents are likely to be threatened by these procedures and may therefore demonstrate resistance, especially the father. In general, Arabic and nonwestem societies discourage and even punish these characteristics, viewing them as egotistical and selfish.

In Western approaches, there is an implicit request on the therapist's part to discuss topics which the Arabic client has been conditioned to avoid throughout the entirety of his or her life. Thus, there is no prior knowledge of how to communicate emotional material. When therapists ask their clients how they feel about some specific experience, Arab clients typically rspond by stating: "I felt nothing" or 'I felt as I normally do." 
These responses are indicitive of the distance which these clients experience between themselves and their feelings. The Arab client simply has no prior experience in the handling of his or her deep emotions. If intimate feelings are to be discussed with these clients, the psychotherapist will first need to educate the client regarding his or her emotions. They will also need to teach their clients to set aside the cultural constraints placed upon emotional expression (pp. 234-236, 238).

Macro cultural psychology additionally directs therapists to discuss broad cultural and political aspects of patients' disturbances. Faisal, for example, would be directed to examine the cultural and political issues we have discussed about his case. This would help him to understand his mother's psychology and her treatment of him. It would soften any personal animosity or blame he directed at her. Additionally, it would help him to understand his own psychology in social terms. His estrangement, ambiguity, vacillation, submissiveness, separation anxiety, fear of marriage, guilt, and compulsive praying would all be made intelligible through a social analysis. This would soften any self-blame or confusion he held about the reasons for his problems. He would be able to replace his guilt over personally failing, with a social understanding that alleviates self-blame. (The American Psychological Association's Task Force on Socioeconomic Status - APA, 2002 - mentions several of these interventions in personal counseling when issues of social class and psychology arise.)

Macro cultural psychology would help Faisal understand his society and become involved in improving it. It would help him circumvent troublesome aspects of his society that has led him, his parents, and many other Saudis to experience a range of psychological problems, from normal 
pathology to severe pathology. Faisal would have a specific direction for changing his relations with women, his parents, his sisters, and himself. In contrast, non-social treatment of psychological problems, e.g., by prayer or medicine, pathologize distress by blaming it on personal failure for disobeying cultural norms. This leads to perpetuating the social causes of the problem and exacerbating the individual's dependence on the treatment. We have seen that Islamic scrupulosity exacerbates guilt and the need to compulsively - and futilely -- pray for atonement.

The only way out of culturally-induced psychological problems is to challenge the culture that induces them (Ratner 2012, c, d, e). Macro cultural psychology is distinctively suited to this endeavor because it explains the details of individual psychological dynamics and interpersonal dynamics in social terms.

\section{End Notes}

A study published in The Journal of the American Medical Association found that drugs widely prescribed to treat severe post-traumatic stress symptoms for veterans are no more effective than placebos and come with serious side effects, including weight gain and fatigue. Anti-depressive and anti-psychotic drugs are ineffective. After six months of treatment with Risperdal, 123 veterans with PTSD were doing no better than a similar group of 124 veterans, who were given a placebo. About 5 percent in both groups recovered, and 10 percent to 20 percent reported at least some improvement, based on standardized measures (Carey, 2011, p. A13).

Research on medication and all kinds of mental illnesses comes to the same conclusion. . Biochemical treatments have general innervating or enervating effects, e.g., on all the neural impulses and psychology that serotonin facilitates; they do not treat particular symptoms. This is why medications are 
interchangeable. Even drugs that are not considered to be antidepressants such as synthetic thyroid hormone, opiates, sedatives, stimulants, and herbal remedies - are as effective as antidepressants in alleviating the symptoms of depression. "When administered as antidepressants, drugs that increase, decrease, or have no effect on serotonin all relieve depression to about the same degree." Furthermore, there is no dose-response curve (higher dose $=$ more effective) for antidepressants. Indeed, drugs are only marginally more effective treatments than placebos, which are three times more effective than no treatment! Actually, the marginal superiority of drugs over placebos is very likely a function of patients' expectations rather than biochemical changes. Patients in the experimental drug condition feel the side effects of the drugs and know they have been treated with drugs. This expectation can account for their improvement, just as placebos lead to improvement. Indeed, "active placebos" which have side effects (e.g., Atropine) are just as effective as antidepressants in treating depression. And "nearly any pill with side effects was slightly more effective in treating depression than an inert placebo. Consequently, medical effects of drugs may actually be placebo effects" (Angell, 2022a, b; see also Joseph \& Ratner 2012 for addition refutation of genetic causes of mental illness).

Whitaker (2011) reports that anti-psychotic drugs are associated with increased prevalence of mental disorders. Mental illness has tripled over the past two decades despite an exponential rise in psychiatric medicating. Patients who take anti-psychotic medication have poorer recovery rates than patients who do not.

Yet the prevalence of these medications has risen exponentially (Wall Street Journal, Nov. 16, 2011, "Psychiatric Drug Use Increases").

Acultural theory of mentalillness and psychology ingeneral is indicated by cross-cultural research on psychopathology which discovers cultural 
variation in the qualitative symptoms and prevalence of psychopathology. It is also indicated by new disciplines of ethno psychopharmacology, social neuroscience, social neuroendocrinology, and social evolution (e.g., the social brain theory) which have demonstrated that human biochemistry and anatomy respond to culture and are culturally variable. Culture and psychology may shape biochemistry more than biochemistry shapes psychology and culture.

\section{Author Notes}

Carl Ratner

Distinguished Visiting Professor

Psychology Department

Imam University

Saudi Arabia

http://www.sonic.net/ cr2

El-Sayed El-Badwi

Clinical Psychologist

Riyadh

Saudi Arabia

sadiekee@hotmail.com 


\section{References}

Abramowitz, J. S., Deacon, B. J., Woods, C. M. \& Tolin, D. F. (2004), Association between Protestant religiosity and obsessive-compulsive symptoms and cognitions. Depression and Anxiety, 20: 70-76.

American Psychological Association (2002). Task Force on Socioeconomic Status. Washington, D.C.: APA.

Angell, M. (June 23, 2011a). The epidemic of mental illness: Why? New York Review of Books, 58, 11, 20-22.

Angell, M. (July 14, 2011b). The Illusions of psychiatry. New York Review of Books 58, 12: 20-22.

Bronfenbrenner, U. (1979). The ecology of human development. Cambridge: Harvard University Press.

Carey, B. (Aug. 3, 2011). Antipsychotic use is questioned for combat stress. New York Times, p. A13.

Dwairy, M., \& Van Sickle, T. (1996). Western psychotherapy in traditional Arabic societies. Clinical Psychology Review, 16, No. 3, pp. 231249.

Foucault, M. (1987). Mental illness and psychology. Berkeley: University of California Press. (originally written 1962).

Fromm, E. (2010). The pathology of normalcy. New York: American Mental Health Foundation Books. (originally written, 1953)

Inozu, M., Clark, D., \& Karanci, A. (2011, in press). Scrupulosity in Islam: A comparison of highly religious Turkish and Canadian samples. Behavior Therapy.

Joseph, J., \& Ratner, C. (2012). The fruitless search for genes in psychiatry and psychology: Time to re-examine a paradigm. In S. Krimsky \& J. Gruber (Eds.), Genetic explanations: sense and nonsense. 
Cambridge: Harvard University Press.

Kleinman, A., \& Kleinman, J. (1985). Somatization: The interconnections in Chinese society among culture, depressive experiences, and the meaning of pain. In A. Kleinman \& B. Good (Eds.). Culture and depression: Studies in the anthropology and cross-cultural psychiatry of affect and disorder (pp. 429-490). Berkeley: University of California Press.

Kuran, T. (2011). The long divergence: How Islamic law held back the Middle East. Princeton: Princeton University Press.

Laing, R. D. (1967). Politics of experience. N.Y.: Pantheon.

Marcuse, H. (1964). One-dimensional man: Studies in the ideology of advanced industrial society. Boston: Beacon Press.

Marcuse, H. (1987). Hegel's ontology and the theory of historicity. Boston: MIT Press. (Original work published 1932)

Okasha, A., et al. (1994). Phenomenology of obsessive-compulsive disorder: A transcultural study. Comprehensive Psychiatry, 35, 3, 191-197.

Ratner, C. (2012a). Macro cultural psychology: Its development, concerns, politics, and direction. In M. Gelfand, C. Chiu, Y. Hong (Eds.), Advances in Culture and Psychology (vol. 3). N.Y.: Oxford University Press.

Ratner, C. (2012b). False consciousness. In T. Teo (Ed.), The Encyclopedia of Critical Psychology. N.Y.: Springer. Ratner, C. (2011a). Macro cultural psychology: A political philosophy of mind. New York: Oxford University Press.

Ratner, C. (2012c). Macro cultural psychology. In T. Teo (Ed.), The Encyclopedia of Critical Psychology. N.Y.: Springer.

Ratner, C. (2012d). Emancipation. In T. Teo (Ed.), The Encyclopedia of Critical Psychology. N.Y.: Springer. 
Ratner, C. (2012e). Capitalism and psychology. In T. Teo (Ed.), The Encyclopedia of Critical Psychology. N.Y.: Springer.

Ratner, C. (2011b). Macro Cultural Psychology. In Jaan Valsiner (Ed.), Oxford Handbook of Culture and Psychology, (chap. 10). New York: Oxford University Press.

Ratner, C. (2011c). Cultural Psychology. In Robert Rieber (Ed.), Encyclopedia of the History of Psychological Theories, (chap. 28). New York: Springer.

Ratner, C. (2011d). Macro cultural psychology, the psychology of oppression, and cultural-psychological enrichment. In P. Portes \& S. Salas (Eds.), Vygotsky in 21st Century Society: Advances in cultural historical theory and praxis with non-dominant communities, (chap. 5). NY: Peter Lang.

Ratner, C. (2011e) Review of Liamputtong, Performing Qualitative CrossCultural Research, and Matsumoto \& Van de Vijver, CrossCultural Research Methods. Forthcoming in Qualitative Research in Psychology.

Ratner, C. (2007). A macro cultural-psychological theory of emotions. In P. Schultz, \& R. Pekrun (Eds.). Emotions in education (chap. 6). N.Y.: Academic Press.

Ratner, C. (1991). Vygotsky's Sociohistorical Psychology \& Its Contemporary Applications. N.Y.: Plenum.

Ratner, C. (1970). The critical psychology of R. D. Laing. Telos, 5, 98-114.

Ratner, C., \& Hui, L. (2003). Theoretical and methodological problems in cross-cultural psychology. Journal for the Theory of Social Behavior, $33,67-94$.

Rieber, R. (1997). Manufacturing social distress: Psychopathy in everyday life. New York: Springer. 
Sartre, J.P. (1963). Search for a method. New York: Vintage Books,

Sass, L. (1992). Madness and modernism: Insanity in the light of modern art, literature, and thought. New York: Basic Books.

Shweder, R. (1990). Cultural psychology - what is it? In J. Stigler, R. Shweder, G. Herdt (Eds.), Cultural Psychology: Essays on comparative human development (pp. 1-43). New York: Cambridge University Press.

Sica, C., Novara, C. \& Sanavio, E. (2002), Religiousness and obsessivecompulsive cognitions and symptoms in an Italian population. Behaviour Research and Therapy, 40, 7 , 813-823.

Steketee, G., Quay, S. \& White, K. (1991), Religion and OCD patients. Journal of Anxiety Disorders, 5, (4), 359-367.

Vygotsky, L.S. (1998). The collected works of L.S. Vygotsky (vol. 5). New York: Plenum.

Whitaker, R. ( 2011). Anatomy of an epidemic: Magic bullets, psychiatric drugs, and the astonishing rise of mental illness in America. N.Y.: Broadway.

Yoriulmaz, O., Gencoz, T., \& Woody, S. (2010). Vulnerability factors in OCD symptoms: cross-cultural comparisons between Turkish and Canadian samples. Clinical Psychology \& Psychotherapy, 17, 110121. 